\title{
Establishment and Characterisation of a Canine Osteo- blastic Cell Line
}

\author{
J M da Fonseca, MK Nagamine, ML.Z Dagli* and IIM da Fonseca \\ Department of Pathology, School of Veterinary Medicine and Animal Science, University of Sao Paulo, Brazil
}

*Corresponding author: Maria Lucia Zaidan Dagli, Laboratory of Experimental and Comparative Oncology, Department of Pathology, School of Veterinary Medicine and Animal Science, University of Sao Paulo, Av. Prof Dr Orlando Marques de Paiva, 87 CEP 05508-900 Sao Paulo, SP, Brazil.

To Cite This Article: JM da Fonseca, MK Nagamine, MLZ Dagli and IIM da Fonseca. Establishment and Characterisation of a Canine Osteoblastic Cell Line. 2020 - 11(1). AJBSR.MS.ID.001590. DOI: 10.34297/AJBSR.2020.11.001590.

Received: 畊 October 22, 2020; Published: 眥 November 30, 2020

\begin{abstract}
Normal canine osteoblast cultures are important in experimental studies for comparisons with osteosarcomas and their responses to test therapies. Although canine osteosarcoma cells are available commercially, normal canine osteoblastic cultures are scarce. Osteoblasts are the main cells present in bones that are responsible for the synthesis of the organic matrix during bone formation, regeneration, healing and remodelling. The purpose of this study was to establish and characterise a canine osteoblast cell line, named COBS. Cells were harvested from a bone callus of a 10-month-old German Spitz female dog. Cells were cultivated in a complete medium specific for canine osteoblast growth. Cells underwent seven cycles of culturing to establish a cell lineage. COBS cells were characterised using cytogenetic analysis and immunofluorescence with osteopontin, alkaline phosphatase, and SPARC (secreted protein, acidic and rich in cysteine; also known as osteonectin). Results confirmed that the cells had 78 chromosomes and expressed the osteoblast biomarkers. COBS cells are now available and can be used as controls in anticancer research.
\end{abstract}

\section{Highlights}

1. Canine osteoblasts cultures are not available commercially

2. Normal osteoblasts are requested to be used as controls for experimental studies

3. Canine osteoblasts can be cultured from canine bone

Keywords: Canine; Osteoblast; Cell culture; Cytogenetics; COBS

\section{Introduction}

Osteoblasts account for $4-6 \%$ of the total resident cells in the bone and are commonly known for their bone building function. Osteoblasts, thus, exert a crucial role in the achievement and maintenance of a correct bone mass, which is accomplished through a close cross-talk with other bone cells, i.e. osteoclasts and osteocytes Capulli et al. [1]. Osteoblasts are derived from mesenchymal stem cells Grigoriadis et al. [2], specialised mesenchymal cells present in bones, that are able to synthesise the dense, crosslinked collagen and specialised proteins, including osteocalcin and osteopontin, which comprise the organic matrix of bone Stein et al. [3]. Osteoblast cultures are becoming more and more important for several purposes, like, for example, bone tissue and bioengineering research Czekanska et al. [4]. Commercial canine osteoblast lineages are scarce, and they are especially important when a normal cell is necessary as controls for studies involving osteosarcoma cells. The aims of this study were, therefore, to establish and characterise a canine osteoblastic cell line for use in experimental studies.

\section{Material and Methods}

The study was performed in accordance with the protocols approved by the Animal Ethics Committees of School of Veterinary Medicine and Animal Science of the University of São Paulo (FMVZUSP), Brazil, Process number 5645170918.

Osteoblasts were collected from a bone callus formed after a tibia fracture in a 10month-old female German Spitz dog. Upon 
anaesthesia, the bone callus was scrapped and the osseous material was immediately collected and cultured in a complete medium, specific for canine osteoblast growth (canine osteoblast growth medium, code: CN417500, Sigma). Cells were recovered and recultured at least seven times to establish an osteoblast cell line. Prior to freezing, the osteoblasts were initially washed with PBS and then trypsinised for $10 \mathrm{~min}$ in a $\mathrm{CO}_{2}$ incubator at $37^{\circ} \mathrm{C}$. After cell detachment, confirmed via microscope analysis, the cells were collected and canine osteoblast growth medium was added with $10 \%$ FBS for trypsin inactivation. The cell suspension was centrifuged for $10 \mathrm{~min}$ at $1200 \mathrm{rpm}$. After centrifugation, the supernatant was discarded and the cells were resuspended in canine osteoblast growth medium. An aliquot was automatically counted in an automatic cell counter (Countess ${ }^{\mathrm{TM}}$, Life Technologies), and the concentration was adjusted to 106 cells/mL with freeze medium $(10 \%$ DMSO $+90 \%$ suspension of cells in FBS). The suspension, already prepared with DMSO, was then aliquoted into properly labelled cryotubes (Corning $®$ ), and these were stored in a freezing tank (Nalgene ${ }^{\circledR}$ Mr. Frosty () ) and placed in a freezer at $-80^{\circ} \mathrm{C}$. After freezing, the cryotubes were quickly removed from the freezer and placed in a drum containing liquid nitrogen until use. Defrosting was performed whenever necessary, by removing the cryotubes from the nitrogen drum and placing them in a water bath at $37^{\circ} \mathrm{C}$. Once the cell suspensions were thawed, canine osteoblast growth medium was added with FBS and then centrifuged for 10 min at $1200 \mathrm{rpm}$. After centrifugation, the cells were resuspended in canine osteoblast growth medium with $10 \%$ FBS and then loaded into Corning® CellBIND $25 \mathrm{~cm}^{2}$ cell culture flasks for cell growth prior to the experiments. This new lineage was called COBS (canine osteoblasts Spitz) (Figure 1).
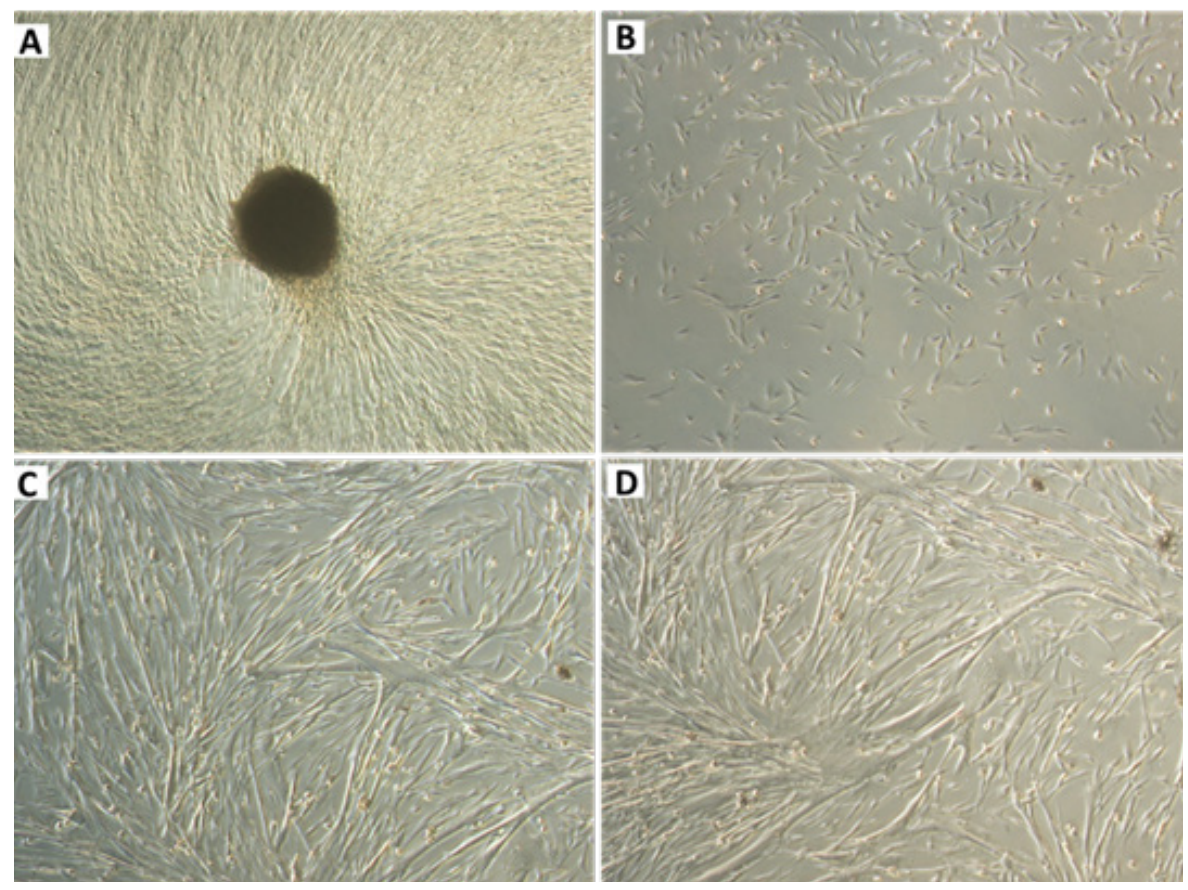

Figure 1A: Representative image of a bone fragment that gave rise to the non-neoplastic canine osteoblastic cell line (canine osteoblasts Spitz, COBS) in culture. Figure 1B: Representative image of the COBS cell line after trypsinisation. Figure 1C\&1D: Representative images of the COBS cell line without trypsinisation 20 days after explanting. Original magnification: $40 x$.

\section{Results}

COBS cells were grown on cover slips in 6-well plates. After 2 days of cultivation in DMEM, the cells were washed with PBS and fixed in $70 \%$ ethanol for $20 \mathrm{~min}$ at $-20^{\circ} \mathrm{C}$. The cells were subjected to antigenic exposure with EDTA pH 9.0 buffer heated to $90^{\circ} \mathrm{C}$ for $20 \mathrm{~min}$. After antigenic exposure, the coverslips were washed with $1 \times$ PBS plus Triton X-100. The coverslips were then incubated overnight in a humid chamber at $4{ }^{\circ} \mathrm{C}$, with antibodies shown in (Table 1). The following day, the slides were washed with PBS containing $0.1 \%$ Triton X-100 and incubated with secondary monoclonal or polyclonal antibodies marked with Alexa Fluor 488 (Dako, Carpinteria, CA, USA, 1:100) for $60 \mathrm{~min}$, in a humid chamber.

Table 1: Antibodies used for the immunofluorescence analysis of the cells from the canine 112 osteoblastic cell line (canine osteoblasts Spitz, COBS).

\begin{tabular}{|c|c|c|c|c|c|}
\hline Antibody & Code & Mono or polyclonal & Mouse or rabbit & Dilution & Subcellular localisation \\
\hline Osteopontin - Abcam & Ab8448 & Polyclonal & Rabbit & 0.111111 & Cytoplasm \\
\hline Alkaline phosphatase - Abcam & Ab108337 & Monoclonal & Rabbit & 0.111111 & Cytoplasm \\
\hline SPARC - Abcam & Ab135601 & Polyclonal & Rabbit & 0.111111 & Cytoplasm \\
\hline
\end{tabular}

Note: SPARC, secreted protein, acidic and rich in cysteine; also known as osteonectin. 
Finally, the slides were washed with PBS containing 0.1\% Triton X-100, mounted with 108 Vectashield (Vector Laboratories, Inc, Burlingame, CA, USA) to prevent depletion of 109 fluorescence and sealed with enamel. We observed the expression of osteopontin, bone alkaline phosphatase, and SPARC in 116 the non-neoplastic canine osteoblastic cell line (canine osteoblasts Spitz, COBS) (Figure 2).

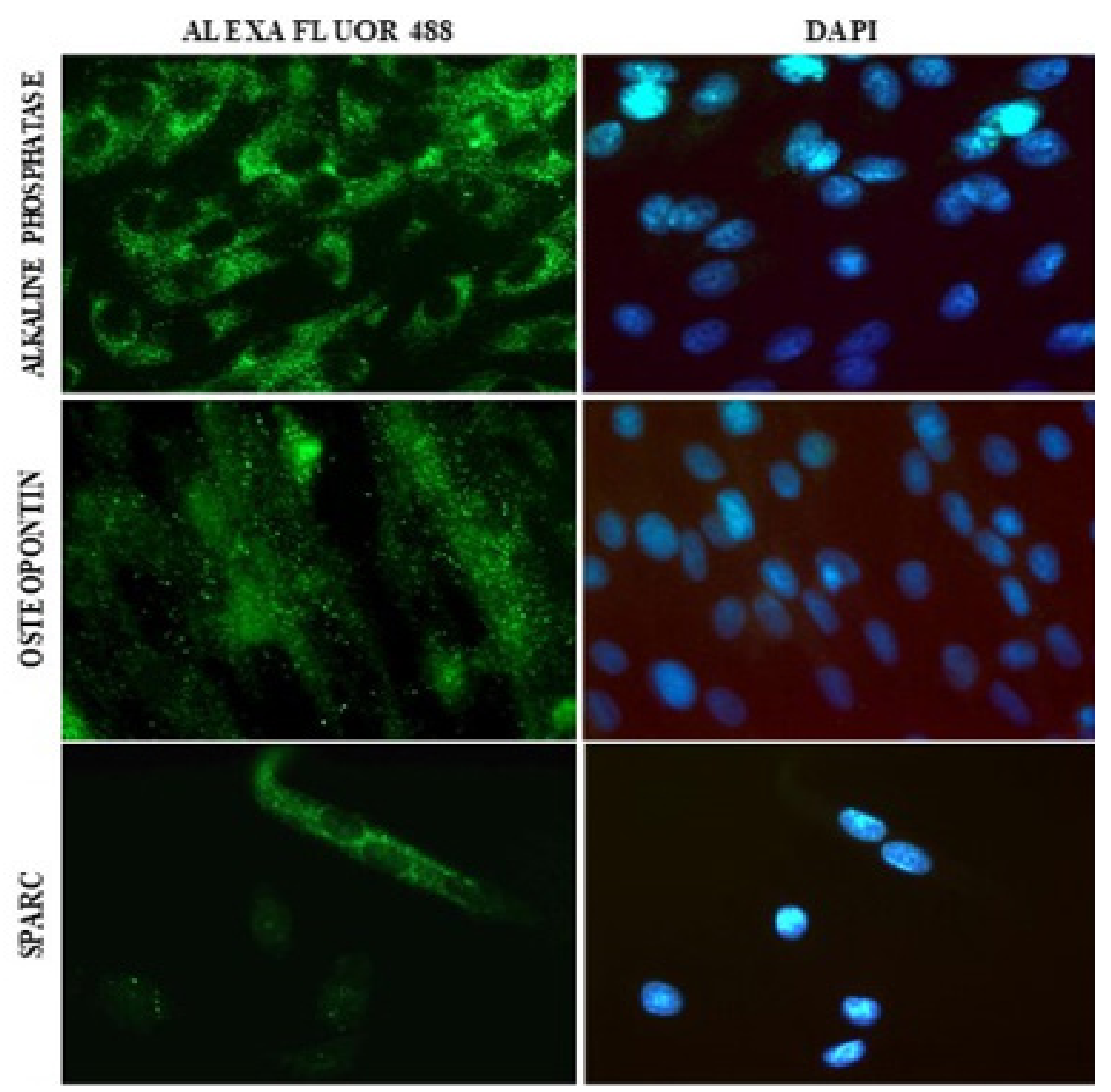

Figure 2: Representative photomicrographs of alkaline phosphatase, osteopontin, and SPARC in the canine osteoblastic cell line (canine osteoblasts Spitz, COBS) revealed by immunofluorescence. Alexa Fluor 488 (green) and DAPI (blue) stained images. Original magnification: $40 \times$. SPARC, secreted protein, acidic and rich in cysteine; also known as osteonectin.

COBS cells were then submitted for cytogenetic analysis. After $24 \mathrm{~h}$ of incubation in an incubator at $37^{\circ} \mathrm{C}$, the colchicinisation step was performed. For colchicinisation, $100 \mu \mathrm{L}$ of colchicine $(0.16 \mu \mathrm{g} /$ $\mathrm{mL}$ ) was added to each $5 \mathrm{~mL}$ subsamples of the final culture and incubated in an oven at $37^{\circ} \mathrm{C}$ for $1 \mathrm{~h}$. After colchicinisation, the contents of the culture bottle were transferred to a $15 \mathrm{~mL}$ Falcon tube, and the cells contained in the bottle were washed with $4 \mathrm{~mL}$ of $1 \times$ PBS, and trypsinisation was performed to collect the cells, which were then centrifuged at $1500 \mathrm{rpm}$ for $5 \mathrm{~min}$ at $37^{\circ} \mathrm{C}$. Using Pasteur pipettes, the supernatant was carefully discarded and the pellet was resuspended by adjusting the vial volume to $5 \mathrm{~mL}$ with hypotonic solution $(0.075 \mathrm{M} \mathrm{KCl})$ at a temperature of $37^{\circ} \mathrm{C}$. The tube was incubated in a water bath at $37^{\circ} \mathrm{C}$ for $10 \mathrm{~min}$, then removed and placed at room temperature. Eight drops of ice-cold fixative
(75\% methanol and 25\% acetic acid) were added and the mixture was allowed to homogenise for another $10 \mathrm{~min}$ at $37^{\circ} \mathrm{C}$. After the hypotonisation period, the material was centrifuged at $1500 \mathrm{rpm}$ for $5 \mathrm{~min}$. For material fixation, the supernatant was discarded and the vial volume was adjusted to $5 \mathrm{~mL}$ with ice-cold fixative. The contents were homogenised and centrifuged again at $1500 \mathrm{rpm}$ for $5 \mathrm{~min}$. The supernatant was discarded with the aid of the Pasteur pipette and the pellet was resuspended with the frozen fixative, adjusting the volume to $5 \mathrm{~mL}$. This procedure was performed two additional times to remove cellular debris from the preparation. Finally, the cell pellet was resuspended in $1 \mathrm{~mL}$ of frozen fixative and stored in a freezer at $-20^{\circ} \mathrm{C}$ until the preparation of the metaphase slides, the staining, and the analyses. After all steps of the material processing were performed, and a cytogenetic pellet was obtained, the dilution 
of the material was adjusted with the fixative so that the material was not saturated. The slide used was first cleaned with absolute alcohol and gauze, and then dipped in distilled water and held at an angle so that a drop with the cytogenetic material (dripped with the aid of a Pasteur pipette) could flow across the slide. After drying the material $\left(24 \mathrm{~h}\right.$ at room temperature, $\left.25^{\circ} \mathrm{C}\right)$, the prepared slides were subjected to staining techniques. The slides were incubated for $30 \mathrm{sec}$ in a trypsin solution diluted 1:250 with Dulbecco's buffer. The digestion reaction was then blocked with a rapid dip of the slides in Dulbecco's buffer solution plus 5\% foetal bovine serum.
The slides were stained with Giemsa (1:30) for $10 \mathrm{~min}$ and washed with distilled water. After drying, the slides were analysed. Images of the chromosomes in metaphase for the assembly of karyotypes of cell line COBS were captured using the Zeiss Axioskop 2 Plus microscope and analysed in the Ikaros 3 program (MetaSystems) at the Human Genetics Laboratory of the Institute of Biosciences of the University of São Paulo (IB-USP). We observed that the normal COBS cell line has 78 chromosomes $(2 \mathrm{n}=78)$, i.e. a normal number of chromosomes for Canis lupus familiaris (Figure $3 \& 4$ ).

Figure 3: Representative photomicrograph of chromosomes in metaphase of the canine osteoblastic cell line (canine osteoblasts Spitz, COBS) Original magnification: $100 \times$.

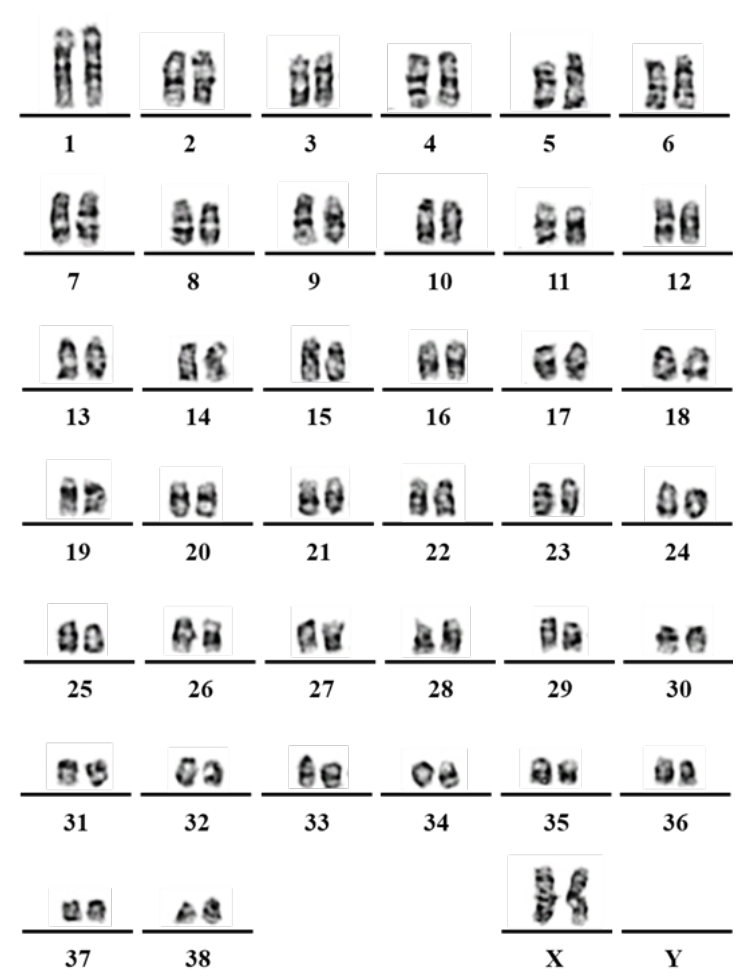

Figure 4: Karyotype of canine osteoblastic cell line (canine osteoblasts Spitz, COBS). Original magnification: 100x. 


\section{Discussion and Conclusions}

Ahs been established canine osteoblastic cell line, called COBS, from a bone callus scraping from a tibia fracture of a 10-monthold female Spitz-German dog. We observed that the normal COBS cell line that was established in our laboratory has somatic cells with 78 chromosomes $(2 n=78)$, which is consistent with the normal number of chromosomes of $C$. lupus familiaris. In this cell line, we observed the expression of bone markers such as alkaline phosphatase, osteopontin, and SPARC. These results confirmed that the COBS cell line is comprised of isolated osteoblasts, which allows their use as controls in antineoplastic research.

\section{Acknowledgements}

This study is part of the thesis presented by Jonathan Mackowiak da Fonseca to the Interunit Graduate Program on Biotechnology of the University of Sao Paulo. Jonathan was the recipient of a fellowship [Process Number 141455/2015-2] from the National Council of Scientific and Technological Development (CNPq) of the Ministry of Science, Technology, Innovation and Communication of Brazil. Ivone Izabel Mackowiak da Fonseca [Process number 2017/12855-1] and Marcia Kazumi Nagamine [Process number 2016/20479-7] are post-doctoral fellows supported by the Sao Paulo Research Foundation, FAPESP

\section{Declarations of Interest}

None

\section{Reference}

1. Mattia Capulli, Riccardo Paone, Nadia Rucci (2014) Osteoblast and osteocyte: Games without frontiers. Arch Biochem Biophys 561: 3-12.

2. A E Grigoriadis, J N Heersche, J E Aubin (1988) Differentiation of muscle, fat, cartilage, and bone from progenitor cells present in a bone-derived clonal cell population: Effect of dexamethasone. J Cell Biol 106(6): 21392151.

3. G S Stein, J B Lian, J L Stein, A J Van Wijnen, M Montecino (1996) Transcriptional control of osteoblast growth and differentiation. Physiol Rev 76(2): 593-629.

4. E M Czekanska, M J Stoddart, R G Richards, J S Hayes (2012) In search of an osteoblast cell model for in vitro research. Eur Cell Mater 24: 1-17. 